\title{
O sentido e a emoção no conteúdo do motivo da atividade de estudo
}

\author{
The meaning and emotion in the content of the reason for the \\ study activity
}

\author{
Valdirene Gomes de Sousa ${ }^{1}$ \\ Lucas Vieira Lemos ${ }^{2}$ \\ Karoline Pignatel Saccon ${ }^{3}$
}

\begin{abstract}
RESUMO
Neste artigo, fazemos uma reflexão na forma de ensaio bibliográfico sobre o conteúdo que move o estudante à atividade de estudo. Com base nos fundamentos teóricos da Psicologia Histórico-Cultural, referente aos elementos básicos da estrutura da atividade humana, por Leontiev e Davídov, analisamos o lugar do sentido e da emoção na atividade do estudante. $\mathrm{O}$ objetivo foi identificar relações dos sentidos e das emoções que surgem como conteúdo do motivo na atividade de estudo. As reflexões resultam das leituras teóricas e das vivências dos três professores autores. Consideramos a atividade de estudo (objeto de análise) pelo viés da estrutura geral da atividade. Dessa correlação, identificamos o desejo, a vontade e a significação como nexos que ligam os sentidos e as emoções ao motivo da atividade, ou seja, como conteúdo deste.
\end{abstract}

Palavras-chave: Atividade de Estudo. Estudante. Emoção. Sentido.

\begin{abstract}
In this article we make a reflection in the form of a bibliographic essay on the content that moves the student to the study activity. Based on the theoretical foundations of HistoricalCultural Psychology, referring to the basic elements of the structure of human activity, by Leontiev and Davídov, we analyzed the place of meaning and emotion in the student's activity. The objective was to identify the relationship of the senses and emotions that arise as a reason content in the study activity. The reflections result from the theoretical readings and experiences of the three author teachers. We consider the study activity (object of analysis) from the perspective of the general structure of the activity. This correlation, we identified the desire, the will and the significance as links that connect the senses and emotions to the reason for the activity, that is, as of this content.
\end{abstract}

Keywords: Study Activity. Student. Emotion. Sense.

\footnotetext{
${ }^{1}$ Doutora em Educação pela Universidade Estadual do Piauí (UESPI). Professora do Centro de Ciências da Educação, Comunicação e Artes (UESPI). Líder do Grupo de Estudos e Pesquisas Histórico-Culturais em Formação de Professores e Prática Pedagógica (GEHFOP). Integrante do Grupo de Pesquisa em Educação Matemática: Uma Abordagem Histórico-Cultural (GPEMAHC/UNESC). ORCID: https://orcid.org/0000-0002-8334-1702. E-mail:valdirenevall@hotmail.com.

${ }^{2}$ Mestre em Educação, Licenciado em Matemática e Psicólogo pela Universidade do Extremo Sul Catarinense. Professor efetivo da Rede Estadual de Ensino de Santa Catarina, Brasil. Integrante do Grupo de Pesquisa em Educação Matemática: Uma Abordagem Histórico-Cultural (GPEMAHC/UNESC). ORCID: https://orcid.org/0000-0003-1083-2233. E-mail: lucasvieiralemos@hotmail.com.

${ }^{3}$ Licenciada em Matemática e Professora em caráter temporário da Rede Estadual de Ensino de Santa Catarina, Brasil. Integrante do Grupo de Pesquisa em Educação Matemática: Uma Abordagem Histórico-Cultural (GPEMAHC/UNESC). ORCID: https://orcid.org/0000-0002-98032312. E-mail: karoline_pignatel@hotmail.com.
} 


\section{O contato com o objeto}

O que constitui e determina o desejo que nos impulsiona à produção desse estudo? Por que direcionamos energia para realizar essa tarefa em detrimento de outras que se apresentam nas atividades em que nos inserimos? O objeto que nos move nessa produção, nos cativa e prende nossa atenção é a atividade humana ${ }^{4}$. Sentimos, como professores, a necessidade de compreender como a aprendizagem e o desenvolvimento do estudante se concretiza pela atividade de estudo. Sempre que atuamos na prática pedagógica reafirmamos essa necessidade.

Percebemos claramente as determinações de uma necessidade depois que ela se manifesta no sujeito. Mas, em que consiste a materialidade desse elemento que leva o sujeito a agir intencionalmente e entrar em atividade? Como uma necessidade externa (coletiva) pode potencializar um desejo expresso em necessidade interna (individual)? Como a vontade determina o controle das ações e tarefas de uma atividade? O que alimenta o conteúdo de um motivo? Enfim, como se educam as emoções e os desejos nesse processo? Longe de encerrá-las, aqui, essas questões fazem parte do contexto dessa análise e nos orientam a tomar alguns componentes da atividade de estudo como objeto de investigação.

O lugar que ocupamos parece ser determinante na forma pela qual os desejos, sentimentos, vontades e emoções se manifestam na relação com o objeto da atividade. A transformação da necessidade em motivo ou finalidade e o sentido gerado (conforme a relação) surgem como determinantes no modo de buscarmos respostas para os problemas ao nosso redor, nas ações, operações e tarefas que realizamos (DAVÍDOV, 1988). Ao inserirmo-nos na atividade de pesquisa, por exemplo, sobretudo pela criação do vínculo com um Grupo de Pesquisa na área da Educação, nos colocamos em condições diferentes de determinações que nos instigam a agir frente às demandas escolares. O estudante continua sendo o mesmo em sala de aula, mas nos orientamos para ele com outro olhar.

4Esse conceito será detalhado na seção seguinte pelo viés da Psicologia Histórico-Cultural, com ênfase nas produções de Leontiev e Davídov, citados no decorrer do texto. A atividade de estudo, na análise, é tomada em sua expressão da atividade humana geral. 
Como pesquisadores, não nos dirigimos ao estudante apenas para formá-lo. Agimos, também, para compreender como ocorre sua formação. Partimos da tese de Davídov (1988) de que a prática objetal é a condição para que o sujeito atue voluntariamente. $\mathrm{Na}$ busca por respostas para atender a necessidade de colocar o estudante em atividade de estudo, realizamos essa pesquisa bibliográfica acerca do que move o sujeito ao estudo. Com base nos fundamentos teóricos da Psicologia Histórico-Cultural, sobre a atividade humana (em especial com base em Vigotski, Leontiev e Davídov), as reflexões também se estende aos elementos que compõem o conteúdo do motivo da atividade de estudo.

A partir do lugar que ocupamos no contato com esse objeto, no ensino e na pesquisa - como professores de matemática no Ensino Fundamental e Médio, na rede Estadual de Santa Catarina (dois autores); no Ensino Superior na graduação do Curso de Pedagogia na Universidade Estadual do Piauí (um autor); e como integrantes de um Grupo de Pesquisa na área da Educação -, direcionamos a análise para o contexto do sentido e das emoções na atividade de estudo. Temos como objetivo identificar relações dos sentidos e das emoções que surgem como conteúdo do motivo da atividade de estudo. Entendemos os desejos e as vontades como nexos pelos quais o conteúdo externo se expressa internamente (como sentido pessoal) e o conteúdo interno se expressa externamente (como emoções que impulsionam a atuação) no processo dialético que caracteriza interiorização e exteriorização como unidade do reflexo psíquico da realidade (DAVÍDOV, 1988).

A pesquisa, em termos de método, se caracteriza pelo que fizemos para analisar essa atividade de uma distância adequada. E, não de tão perto a ponto de cegarmos, envolvidos por suas emergências imediatas; nem de tão longe de modo que perdêssemos o contato com a vida concreta dos sujeitos escolares. Tomamos como unidade de análise a relação entre a atividade humana (geral) e a atividade de estudo (singular). As leituras e reflexões teóricas realizadas em consonância com nossas vivências surgem como o contexto particular mediador dessa análise, com base nos autores apresentados durante a exposição.

Nesse contexto, as vivências em escolas públicas e na universidade revelaram, para nós, a importância da orientação do ensino para o estudante 
reconhecer o estudo como atividade principal (LEONTIEV, 2004). Ou seja, reconhecer as verdadeiras razões que o movem à atividade. Chama-nos a atenção, na escola, as orientações e tentativas para convencer (fisgar) o estudante alheio ao estudo. Não raramente, essas tentativas se reduzem ao tratamento (utilizam-se, por vezes, o termo acolhimento) das demandas afetivo-emocionais desconexas do processo de aprendizagem escolar. Percebemos que o sentido da escola na vida do estudante, nesse viés, perde o contato com suas verdadeiras finalidades.

Por outro lado, pensar a atividade de estudo aquém das demandas afetivoemocionais é reduzir o processo de aprendizagem a aspectos cognitivos isolados, como se os afetos e emoções não fossem inerentes ao sujeito na realização de sua atividade. Pesquisas acerca do sentido e das emoções (GAZZOTTI; SOUZA, 2019; ASBAHR, 2014; ASBAHR; SOUZA, 2014; PIOTTO; ASBAHR; FURLANETO, 2017; MENDONÇA; ASBAHR, 2018) têm evidenciado a importância de avaliar o sujeito em unidade nas relações com o meio externo. Nesse estudo, destacamos: 1) as significações e o sentido pessoal ligado ao motivo da atividade; 2) a unidade afetivo-cognitivo como base para superar a dualidade entre razão e emoção na atividade. Entendemos que essas relações apresentam elementos substanciais para uma reflexão que visa não separar aspectos emocionais dos racionais na formação da consciência, porém, sem tratá-las como a mesma coisa.

Para Davídov e Márkova (1987), o avanço da psicologia pedagógica está em não considerar o estudo em partes isoladas do desenvolvimento, mas como atividade integral, avaliando o estudante em sua concretude, como personalidade em transformação. Para os autores, na avaliação da atividade integral de estudo,

os indicadores de eficiência não serão apenas as ações de estudo do escolar, mas também a proposta, por ele mesmo, das tarefas e objetivos destas ações; não apenas os procedimentos de trabalho dele com o material didático, mas também os meios de controle e avaliação, de autorregulação do próprio comportamento de estudo, etc. (DAVÍDOV; MÁRCOVA, 1987, p. 317).

Essas reflexões levaram-nos a hipótese de que o sentido da atividade - que para Leontiev (2004) tem ligação com a necessidade, o motivo e a finalidade da atividade - age na unidade das relações que movem o estudante pelo menos de 
duas maneiras: 1) como vontade, com caráter educativo dos desejos, levando o sujeito voluntariamente (consciente) às ações orientadas aos fins da atividade; 2) nas emoções, também com caráter educativo, resignificando o êxito ou fracasso na realização das tarefas. As emoções, nesse caso, se refletem como resultado e não como causa da atividade, ainda que emoções distintas possam caracterizar contingências no rol de múltiplas determinações que motivam a atuação humana.

Mas, para compreendermos o processo em que ocorrem essas manifestações de desejo e emoção e suas ligações com o sentido e a vontade, direcionamo-nos agora ao estudo sobre a estrutura da atividade humana de forma geral, orientando-nos para as particularidades da atividade de estudo.

\section{A estrutura da atividade: fundamentos para a atividade de estudo}

Para a análise dos elementos que impulsionam o sujeito à atuação prática, reportamo-nos à Teoria da Atividade. Leontiev (2004; 1978), contemporâneo de Vigotski, desenvolveu essa teoria ao criar um método de análise do conteúdo e da estrutura da atividade humana. O autor dedicou-se à investigação e explicação do surgimento e do desenvolvimento da consciência na relação do homem com o meio externo. Para tanto, contrapõe o estágio de desenvolvimento psíquico animal ao processo de desenvolvimento do ser primitivo. Conclui que as condições objetivas internas do aparelho psíquico do homem, determinadas pelas condições objetivas externas de vivência em grupo e transformação da natureza, características da espécie, foram causas propulsoras da superação ao estágio psíquico superior denominado de consciência (LEONTIEV, 2004; 1978).

A Psicologia Histórico-Cultural, como concepção teórica de homem e de mundo, parte do princípio de que a relação essencial da atividade humana é a produção intencional das condições materiais de vida (MARX; ENGELS, 1974). Essa perspectiva, com base no materialismo histórico dialético, compreende que a consciência surge e se desenvolve a partir da inserção dos sujeitos nas atividades que se constituíram historicamente com a evolução da espécie humana. $\mathrm{O}$ mundo se apresenta para o homem sob as condições de atender as necessidades práticas 
do seu universo material. Desde cedo, aprende-se e apreende que as ações se orientam para uma finalidade (LEONTIEV, 2004; DAVÍDOV, 1988).

No que se refere às múltiplas determinações do que move um sujeito a agir, não podemos ignorar que a estrutura que determina a realização das atividades e, consequentemente, o desenvolvimento da consciência dos sujeitos, tem base nas particularidades das relações de produção capitalista. Essa condição, segundo Leontiev (2004), deve ser considerada na análise particular de qualquer atividade realizada nesse contexto. Assim sendo, o desenvolvimento do motivo da atividade de estudo, o sentido e as significações geradas, bem como, as vontades, desejos e emoções, estão subordinadas a essas relações (DAVÍDOV, 1999).

"Não é a consciência que determina a vida, mas a vida que determina a consciência” (MARX; ENGELS, 1974, p. 21). Essa lei de natureza humana revela seu conteúdo universal nas relações que se constituem dos sujeitos entre si e com o mundo. Ao agir sobre o meio, sob as determinações do próprio meio, se origina um movimento dialético que caracteriza a tomada de consciência do sujeito sobre a realidade. Isso ocorre, primeiramente, pelo reflexo psíquico que "resulta de uma relação ação, de uma interação real entre um sujeito material vivo altamente organizado e a realidade material que o cerca. [...] O reflexo psíquico não pode aparecer fora da vida, fora da atividade do sujeito" (LEONTIEV, 2004, p. 99).

Tal pressuposto se torna essencial se compreendemos a apropriação dos elementos de uma atividade, conforme Leontiev (2004) e Davídov (1988), como um ato social, que ocorre somente depois que o sujeito experimenta o contato com seus objetos pela inserção na atividade externa. Assim, para que o estudante efetivamente se reconheça no estudo é necessário que se insira nos espaços de aprendizagem, se relacione com os objetos de conhecimento, se sinta pertencente a essas relações assumindo compromissos com as tarefas que deve realizar, entre outras relações que se apresentam a ele pelo fato de ser estudante. Este, precisa experimentar, pela primeira vez, a aprendizagem como um resultado das ações de sua atividade. O sentido gerado, que encontra substâncias na prática objetal relacionada à atividade (DAVÍDOV, 1988), resultará do motivo, não o contrário. 
O contato direto com o objeto da atividade de estudo e as relações de convergência entre seus elementos estruturais, principalmente na produção do sentido em que os motivos e as finalidades da atividade encontram uma conexão, surge para nós como o combustível que move o sujeito à atividade, corroborando com a tese de Davídov (1999, p. 2) de que "um desejo é o núcleo básico de uma necessidade". O contato prático do sujeito com o objeto da atividade, gera a possibilidade de tomá-lo para si como objeto de seus desejos e vontades.

Ao contrário, as condições das relações que nos distanciam da vivência com o objeto parecem enfraquecer a vontade (voluntariedade) e, consequentemente, a necessidade de agir efetivamente (LEONTIEV, 2004). A necessidade se desloca para o fim da produção, forçando-nos a pular e ignorar etapas, e as emoções passam a responder diretamente ao resultado e não ao processo. Pode-se dizer que atualmente, como tratava 'a velha psicologia' (VIGOTSKI, 2001), há uma tendência ao deslocamento das emoções para o resultado final (produto da atividade) em detrimento do processo.

Para Davídov (1988, p. 30), "na psicologia se diferencia a atividade objetal externa da atividade interna. [...] A atividade interna é secundária: se forma no processo de interiorização da atividade objetal externa". Não se trata de uma reprodução mecânica do mundo externo no cérebro do homem, mas de transformações qualitativas na apreensão desse conteúdo e nas formas como se organiza a atividade interna a partir da externa, necessariamente, mediatizadas. Esse conteúdo se reflete ao psiquismo do homem por meio de

contatos práticos com o mundo dos objetos, contatos práticos que por isso se subordinam necessariamente às propriedades, relações, vínculos do mundo, com caráter independente. Consequentemente, o "aferente" que dirige a atividade é primariamente o objeto e apenas secundariamente sua imagem como produto subjetivo da atividade, que leva em si seu conteúdo objetal. Aqui tem lugar um trânsito duplo: objeto $\rightarrow$ processo da atividade e atividade $\rightarrow$ seu produto subjetivo (DAVÍDOV, 1988, p. 254).

A realidade está para o sujeito, com suas leis próprias, independente do conteúdo sensível que reflete dela em seu psiquismo. O sujeito não reflete a 
realidade de fora. Ao contrário, ao estar nela - como expressão singular das relações universais que envolvem sua constituição como ser humano - revela, a partir do reflexo psíquico, a possibilidade da tomada de consciência das coisas e de si mesmo nas relações. Por isso, não age mais de forma direta aos estímulos como os animais, mas pela organização do conteúdo externo em seu psiquismo, que exerce relativo controle, tal qual se organizam as atividades externas.

A tomada de consciência, produto subjetivo que tem origem na imagem dos objetos refletida no cérebro como base da consciência, também mediatiza e regula a atividade (DAVÍDOV, 1988). Nesse aspecto, ela é delimitada pela impossibilidade de acesso imediato a todas as propriedades dos objetos e relações. O reflexo psíquico "depende da atividade do sujeito, obedece às relações vitais que ela realiza, não pode ser do parcial, como parciais são as próprias relações” (LEONTIEV, 2004, p. 99). Eis o que distingue o reflexo psíquico (relação primária com o objeto que eleva o conteúdo externo ao psiquismo) da consciência propriamente dita (relação secundária como produto subjetivo mediatizadora do processo). O reflexo psíquico está na relação objeto $\rightarrow$ processo da atividade, a consciência, como resultado do primeiro movimento, na relação atividade $\rightarrow$ seu produto subjetivo (DAVÍDOV, 1988). A consciência objetivada se torna condição do reflexo consciente da realidade por seu caráter mediatizador, como ocorre na atividade externa. Essa semelhança ao movimento externo, base da determinação da atividade humana ao mundo externo, Davídov (1988, p. 28) denomina de plasticidade. "Nesse processo tem lugar a "palpação" do objeto por parte da necessidade, sua objetivação, sua conservação em motivo concreto da atividade”.

Talvez um dos erros principais em nossa sociedade atual, sobretudo na compreensão psicológica do sujeito, seja a inversão dessa ordem, colocando na análise da realidade o produto subjetivo independente da relação com os objetos das atividades. O reflexo psíquico antecede a tomada de consciência que, por sua vez, limita-se às mediatizações pelas atividades externa e interna. Não tomamos consciência de tudo que elevamos ao plano psíquico, tão pouco de todo o conteúdo da realidade. À medida que agimos nas relações parciais (LEONTIEV, 2004), mediados pela atividade externa e pela consciência, recortamos parte da realidade apreendida em detrimento de um amplo universo de todas as outras. Tomamos 
consciência sobre o reflexo que apreendemos nos limites das mediações de nossa prática concreta, que envolve em unidade atividade externa e interna.

Se estudarmos profundamente o conteúdo de um objeto, suas formas e leis gerais, compreendermos suas relações e os nexos gerais que nos permitem identificar suas universalidades e singularidades (DAVÍDOV, 1988), tendemos a compreendê-lo em sua integralidade. Entendemos a prática concreta como o particular que revela (em unidade) o singular e o geral das coisas que se refletem nas generalizações que constituem a tomada de consciência sobre elas. Quanto mais se compreende as características gerais dos objetos, mais concreta se revela a consciência, mais o que se reflete sobre o mundo objetivo e suas relações, no individual ou no coletivo, representa a concretude da realidade, considerando que não há uma consciência absoluta que antecede a atividade externa.

A estrutura da atividade surge e se desenvolve primeiro externamente, apenas depois se torna conteúdo interno do sujeito ativo no processo (LEONTIEV, 2004). Vale salientar que ser ativo no processo não é uma escolha do sujeito, mas uma condição. Este pode ser mais ou menos envolvido nas relações. A criança, por exemplo, compreende a existência da escola antes de entrar nela pela primeira vez, ou seja, a escola faz parte de suas relações já numa atividade antecedente, na brincadeira (atividade de jogo), se torna para a criança um objeto de desejo e vontade mediado pela imagem que toma para si de escola.

Contudo, quando a criança se reconhece como estudante pela primeira vez, ao ser inserida nas relações escolares e ter que cumprir as tarefas referentes à posição que ocupa nas relações sociais, é que passa efetivamente a se apropriar dos elementos da atividade de estudo. Nesse momento, os objetos da atividade de estudo se tornam seus objetos de desejo e vontade. As necessidades, motivos e finalidades próprios da atividade passam a ser também elementos de sua consciência, razões pelas quais cumpre as tarefas e se envolve nas ações de estudo. O estudante à margem da possibilidade de ingressar na escola, que não estabelece um sentido concreto dela em suas relações, sofre as consequências dessa marginalização na sua vida e em sua consciência. 
No núcleo do processo da atividade, Leontiev coloca a personalidade. $\mathrm{Na}$ "análise posterior do movimento da atividade e das formas do reflexo psíquico dela gerados, faz-se necessário incorporar o conceito do sujeito concreto, da personalidade como momento interno da atividade" (LEONTIEV, 1978, p. 125). A personalidade é, para o autor, o sujeito concreto a partir do qual a atividade, por sua própria natureza, é objetivada. Portanto, não podemos analisar o estudante, enquanto sujeito concreto, isolado da atividade em que está inserido. O desejo do estudante pelo estudo não pode ser visto em si mesmo, como mera expressão subjetiva individual (relativa). Há de se considerar as relações sob as quais ele manifesta seus anseios, por mais "primitivos" que pareçam.

Leontiev (1978) e Davídov (1988) põem em unidade os elementos que movem e orientam o sujeito à atividade e em sua realização. As necessidades, os motivos e as finalidades se correlacionam e transformam mutuamente conforme as condições objetivas de efetivação da atividade, nas mesmas circunstâncias em que ocorrem as correlações e transformações entre atividade, ação e operação. As referidas transformações se originam na atividade objetal externa em unidade com o reflexo psíquico, nas relações do homem com o mundo externo. Segundo Davídov (1988, p. 30), "o reflexo psíquico é considerado como gerado no processo da atividade e logo como mediatizador desta, não pode ser entendido fora da atividade integral".

A análise do sujeito concreto demanda tratar em unidade a atividade externa e interna, porém, não como identidade. Atemos-nos aqui ao duplo papel das necessidades nesse processo para observamos alguns nexos dessa correlação dialética de opostos inerentes. Por uma via, a necessidade se caracteriza como condição interna, por outra como orientadora e reguladora da atividade concreta nas relações externas com os objetos:

$\left(1^{\circ}\right)$ No primeiro caso a necessidade aparece apenas como estado de carência do organismo, estado que por si mesmo não é capaz de provocar nenhuma atividade definidamente orientada; seu papel se limita a estimular as funções biológicas e a excitação geral da esfera motriz que se manifesta nos movimentos de busca não orientados. $\left(2^{\circ}\right)$ Apenas como resultado de seus "encontros" com o objeto correspondente, a necessidade pode, pela primeira vez, orientar e regular a atividade (DAVÍDOV, 1988, p. 254). 
A compreensão da transformação e objetivação das necessidades na consciência como um elemento da unidade que constitui correlações complexas da atividade humana, possibilita sua análise na estrutura da atividade no coletivo e no individual sem dissociá-los. Nessa unidade, estão os nexos essenciais que agem como elos mediadores, vinculando o conteúdo que insita o sujeito a agir ao que o orienta na atividade, tendo em vista sempre a prática objetal. Trata-se, pois, de objetos de carência para o seu organismo e que constituem as atividades no âmbito coletivo. Poderíamos dizer: objetos que estão mais relacionados à emoção, que atende carências afetivas. Objetos relacionados ao sentido, que corresponde mais as razões de existência das coisas. São apropriados, pelo sujeito, e significados a partir das mediações de sua vivência relacionadas a eles e passam a orientar e regular a atividade (DAVÍDOV, 1988).

Como exemplo, destacamos as correlações complexas entre: objetivos, tarefas e metas, que expressam os nexos entre motivos e finalidades da atividade; significações e sentidos, que expressam os nexos que ligam necessidades, motivos e finalidades com as ações e operações correspondentes na realização das tarefas da atividade; tendências e desejos, que se expressam na base das necessidades e dos motivos na unidade internamente como plasticidade da atividade; emoções e sentimentos que expressam os efeitos da atividade no sujeito singular a partir de suas carências e como resultado da orientação e do controle de suas necessidades.

$\mathrm{Na}$ prática, ocorrem as transformações mútuas entre os componentes estruturais da atividade como mostra o esquema: as "necessidades $\rightleftarrows$ motivo $\rightleftarrows$ finalidade $\rightleftarrows$ condições para obter a finalidade e correlacionados com estes a atividade $\rightleftarrows$ ação $\rightleftarrows$ operação" (DAVÍDOV, 1988, p. 31). As flechas representam as transformações entre os elementos do conteúdo interno e externo ao homem como base para a formação da consciência. Nessa perspectiva, a análise psicológica da atividade possibilita a distinção dos nexos necessários da atividade aos contingentes, ainda que se compreendam ambos como conteúdo da consciência, determinante dos impulsos propulsores e inibidores das ações e operações que o sujeito realiza. Tal distinção é 
importante na medida em que refletimos sobre o sujeito concreto, na base de sua consciência, no que se apresenta para ele como essencial e em sua conduta.

A identificação do conteúdo externo da atividade pelas manifestações do conteúdo interno - como expressão singular dos conceitos apreendidos em forma de signos, significações e sentidos - revela a tomada de consciência do sujeito sobre a atividade que realiza e sua formação a partir dela. Essa relação expressa os nexos ligados com a estrutura geral da atividade (essenciais) e os nexos ligados à vida particular do sujeito que, direta ou indiretamente, determinam sua atuação, agindo em suas emoções e desejos (LEONTIEV, 1978). De acordo com Davídov (1988), as tendências (externas) e os desejos (internos) compõem o núcleo da pulsão humana que, no movimento de exteriorização - quando o sujeito atua no meio aparecem como necessidades, motivos e finalidades da atividade.

A tomada de consciência das relações do mundo externo, no movimento de interiorização, fornece ao sujeito um complexo de possibilidades, convergentes ou não com sua consciência, como transformação e desenvolvimento ulterior para além da atividade externa. Davídov (1988, p. 256), parafraseando Leontiev, diz que "o processo de interiorização não consiste no translado da atividade externa ao já existente "plano interno da consciência", mas na produção e formação desse plano". Destacamos como exemplo desse movimento dialético "o deslocamento dos motivos para as finalidades das ações" que, para Leontiev (2004, p. 115), "permite compreender psicologicamente como novas necessidades podem aparecer e como se transforma o seu tipo de desenvolvimento".

Para compreendermos a função do desejo como base da necessidade, na atividade e na consciência do sujeito, recorremos à máxima vigotskiana de que toda atividade humana é significada e, nesse processo, ocorre a produção de sentidos vivenciados em diferentes situações sociais. Tais sentidos perpassam por motivos, emoções e afetos que (diferente dos animais) nos humanos respondem a um sistema complexo de linguagem e são determinados pela forma pela qual se estrutura a atividade externa, que é apreendida e transmitida historicamente pelo homem, de geração em geração, como conhecimento (LEONTIEV, 2004). 
Embora a necessária conservação da condição biológica no homem - ao superar o psiquismo animal e constituir-se humano (LUKÁCS, 2012), mantendo na base do seu organismo uma ligação com a natureza animal - o sujeito, como ser social, não age mais por reações inatas (primitivas) ao satisfazer as necessidades vitais respondendo instintivamente às circunstâncias imediatas.

O homem age, como dito anteriormente, determinado por reações adquiridas (mediatizadas), decorrentes da aprendizagem e do desenvolvimento que se constitui ao longo de sua formação. Isso ocorre ao ser inserido nas relações sociais - algumas relações institucionalizadas, como o caso da escola - consciente das suas ações, das finalidades para onde se orienta e de suas necessidades (LEONTIEV, 2004). Na escola, um dos desafios dos professores é objetivar a necessidade de aprendizagem não somente como "motivo apenas compreensível" (não eficaz), mas como um motivo "verdadeiramente eficiente" (eficaz), que o faça agir na atividade e o oriente nela (LEONTIEV, 2004).

A condição de natureza humana que surge da superação das reações inatas a um novo modo de (re) agir ao mundo - como ser ativo na transformação do meio e, consequentemente, na transformação de si mesmo como ser consciente - se caracteriza como um problema básico que concretiza socialmente a necessidade de existência da escola. Todo sujeito, para acompanhar a evolução humana, necessita de uma instrução básica para desenvolver sua atividade cognoscitiva e se inserir mais efetivamente nas relações sociais, escolhendo o lugar que mais lhe convém atuar na sociedade.

Para Vigotski (2018, p. 63) - quem mostrou as reações inatas e as adquiridas em unidade, porém, diferenciando-as, colocando os fatores sociais com predominância sobre os biológicos - "toda educação é de natureza social, queira-o ou não”. Antes mesmo de nascer, o ser humano está determinado a se apropriar da estrutura do meio, histórica e culturalmente, desenvolvida pela humanidade.

A elucidação desses fundamentos teóricos de categorias próprias da Psicologia Histórico-Cultural, idealizada por Vigotski, apresenta como o homem se constitui concretamente na relação com os outros e com o mundo, mediados por múltiplas determinações sociais, históricas e culturais. Assim, o conteúdo que 
compõe a materialidade da unidade de análise que estabelecemos nesse artigo, na compreensão da conduta do estudante diante da atividade de estudo - relação entre sentimentos e significações como expressão do sentido e como substância do desejonecessidade-motivo pelo estudo -, se revela na explicação do conceito de atividade como base do desenvolvimento da consciência (LEONTIEV, 2004).

Entendemos que a estrutura escolar vigente não dá conta de organizar o meio de modo que prepare o sujeito (estudante) para se inserir e posicionar no meio social consciente de suas ações, mas alheio a elas. Para que o estudante compreenda como ele se constitui humano, como ocorre a sua formação e agir a favor dela, torna-se necessária a transformação da estrutura escolar (do modo como se organiza o meio onde ocorre a aprendizagem).

Vimos que o único educador capaz de formar novas reações no organismo é a sua própria experiência. Só aquela relação que ele adquiriu na experiência pessoal permanece efetiva para ele. É por isso que a experiência pessoal do educando se torna a base principal do trabalho pedagógico. Em termos rigorosos, do ponto de vista científico, não se pode educar o outro. É impossível exercer influência imediata e provocar mudança no organismo alheio, é possível apenas a própria pessoa educar-se, ou seja, modificar suas reações inatas através da própria experiência (VIGOTSKI, 2018, p. 63).

Isso requer a transformação na estrutura escolar de tal modo que o estudante não reduza sua experiência de estudo a uma vivência passiva. Ao contrário, para que atue de forma verdadeiramente autônoma. Para tanto, a dinâmica escolar necessita não apenas considerá-lo ativo no processo, mas colocálo efetivamente em atividade. As estruturas que tratam o estudante como um objeto passível de transformação, como se pudessem ser moldados para responder com reproduções de memórias prontas e como seres acríticos, que "entregam" ao professor a responsabilidade por sua aprendizagem, não consideram o sujeito ativo tão pouco o colocam em atividade em sua formação.

Essas escolas submetem os estudantes a experiências condicionadas (muitas vezes traumáticas e sem sentido na esfera pessoal) reduzidas a relações abstratas, que não refletem o conteúdo da realidade na unidade dialética que caracteriza a vida concreta do sujeito (resta ao estudante aceitar significações forçadamente). 
Contudo, a vida não se apresenta dessa forma, mecânica para o sujeito, mas a partir da atividade prática que realiza e sua tomada de consciência por meio das significações que refletem os objetos dessa atividade.

A realidade aparece ao homem na sua significação, mas de maneira particular. A significação mediatiza o reflexo do mundo pelo homem na medida em que ele tem consciência deste, isto é, na medida em que seu reflexo do mundo se apoia na experiência da prática social e a integra (LEONTIEV, 2004, p. 101).

A significação que não condiz com a prática concreta, com a experiência da prática social, não a integra. Uma vez que a significação é para o sujeito o modo particular pelo qual reflete conscientemente a prática social e a sua consciência, a partir destas significações, não está integrada. O reflexo consciente não revela para o sujeito a realidade concreta, como ela realmente se apresenta, mas como uma abstração. Para Leontiev (2004, p. 104), “o sentido se exprime nas significações [...] como o motivo (se exprime) nos fins" da atividade.

Desse modo, a significação - "forma ideal, espiritual da cristalização da experiência e da prática sociais da humanidade" (LEONTIEV, 2004, p. 104) - se revela abstrata e superficial ao sujeito que não se apropria do conteúdo delas. As generalizações aceitas abstratamente não geram sentido positivo, pois, a partir delas, os motivos não convergem com as finalidades da atividade. Ocorre uma "ruptura" entre o que move o sujeito e o que o orienta.

Contudo, essas significações também agem na correlação entre emoções $\rightleftarrows$ sentimentos $\rightleftarrows$ desejos $\rightleftarrows$ necessidades na unidade do psiquismo (razão/emoção; cognitivo/afetivo). Se observarmos, atualmente, a postura negacionista com relação ao coronavírus, perceberemos que os sujeitos que compreendem superficialmente os elementos biológicos do vírus e sua contaminação tendem a uma conduta semelhante de intolerância a tudo e a todos que contestem essa significação. Manifestam fortemente o desejo por uma sociedade 'perfeita' que não condiz com as ações que realizam. De um ponto de vista psicopatológico, apresentam um ego ingênuo, que respondem com predominância as suas necessidades internas mais profundas, em detrimento da orientação e regulação das atividades externas que se apresentam necessárias para a harmonia coletiva. 
Quando o sujeito interage com os outros sujeitos e com os significados sociais já construídos ao longo da existência humana, ele atribui um sentido àquele significado social, a partir de sua vivência. É dessa forma que se pode compreender como dois sujeitos podem vivenciar a mesma realidade, porém apreendê-la de maneira diferente (GAZZOTTI; SOUZA, 2019, p. 9).

A apreensão da realidade sempre será subjetiva, isso é uma condição humana da tomada de consciência a partir do reflexo psíquico. Em contrapartida, a realidade sempre se apresenta integral, como realmente é independentemente dos sujeitos que fazem parte dela. Assim, embora os sujeitos concretos vivenciem a mesma realidade, as vivenciam de maneiras diferentes mediados por condições externas e internas particulares. O mesmo sujeito pode vivenciar uma situação muito semelhante e aprendê-la distintamente.

O que se apresenta comum é que o conteúdo apreendido, imediatamente ou mediado pela consciência no reflexo imediato do sujeito da vivência, determina sua conduta e atitudes. Em outras pesquisas que realizamos, por exemplo, quando por alguma razão não obtemos o êxito desejado, as emoções e sentimentos gerados foram completamente diferentes dessa (que estamos obtendo êxito no processo), gerando sentimentos negativos (ao invés dos positivos que estamos vivenciando), embora grande parte do processo tenha ocorrido semelhante.

Para Davydov (1999, p. 2), as "necessidades e desejos compõem a base sobre a qual as emoções funcionam [...] as emoções e necessidades não podem ser consideradas separadamente, pois as necessidades se mostram através de manifestações emocionais". O autor coloca as emoções na estrutura da atividade como o elemento que possibilita o sujeito a tomada de decisão no cumprimento de uma tarefa, ou seja, para atingir seu objetivo e as metas estabelecidas. A emoção "fornece a permissão" para o sujeito pôr-se ou recusar-se a realizar uma tarefa na presença ou falta de subsídios para tal realização. Pode-se dizer que a emoção age como um elo da atividade externa com a interna, do que é primário (objeto de uma necessidade) com o que é secundário (desejo, sentimento e a necessidade que se expressa para o sujeito com relação ao objeto). 
A realidade objetiva é a origem das emoções e dos sentimentos. $\mathrm{O}$ sujeito tem uma atitude emocional para os objetos e fenômenos do mundo real e os sente de distintas maneiras segundo as relações objetivas particulares em que se encontra com eles. As emoções e os sentimentos são uma das formas em que o mundo real se reflete no homem (BLAGONADEZHINA, 1978, p. 355).

Se tratarmos as necessidades e os desejos, assim como as emoções e os sentimentos, na unidade da consciência, inseparáveis nas ações realizadas pelo homem, podemos pensar na possibilidade lançada por Davídov (1999) sobre a questão de como o desejo ("orgânico e espiritual") se transforma em necessidade. Para tanto, há de se compreender que a unidade desses elementos só se manifesta no sujeito concreto. $\mathrm{O}$ sentimento de medo, por exemplo, que age diretamente nas emoções, pode ser descrito e explicado fora do sujeito, mas apenas quando este o manifesta em sua vida particular, ao vivenciar as ações e operações que realiza ou deixa de realizar, que acessamos o conteúdo concreto das transformações que ocorrem. Assim, podemos identificar o conteúdo das emoções e sentimentos: 1) se estão ligados às necessidades individuais que o sujeito apresenta por suas carências; 2) se respondem efetivamente às condições de realização de uma atividade.

A intensidade das emoções e dos sentimentos depende, em primeiro lugar, do significado que tem para os homens os objetos e fenômenos que os motivam que, por sua vez, depende de como se organiza a vida do sujeito, da importância nela de uns ou outros fenômenos ou atividades, das necessidades principais para ele, de suas atitudes com respeito às exigências sociais, quais motivos o impulsiona e quais as finalidades ele persegue em sua atividade (BLAGONADEZHINA, 1978, p. 357).

Uma crise de ansiedade decorrente de um sentimento de medo pode ser identificada igualmente em duas pessoas a partir dos modos que manifestam. Apesar disso, as duas crises podem conter conteúdos completamente diferentes quando observadas na unidade da atividade integral (interna e externa). Uma mãe que teme perder a possibilidade de sustento de um filho revela um conteúdo diferente de um estudante que teme realizar uma prova de matemática porque não sabe o conteúdo. A análise reduzida ao individual mostra que ambos têm um problema psicológico para lidar com as situações adversas. A análise reduzida ao 
coletivo mostra que o meio determina tal transtorno, colocando ambos os sujeitos "no mesmo embrulho", como reprodução idêntica das relações postas socialmente.

A análise integral da atividade, que trata em unidade a relação externa com a interna, ainda que enfatize o meio como propulsor, não reduzirá a conduta do sujeito às condições externas em detrimento das internas, nem o contrário. Compreende-se, assim, a natureza e a particularidade das formas em que se manifestam a ansiedade e as diferentes maneiras de tratá-la. As condições de transformação do meio escolar - que levem à aprendizagem e ao desenvolvimento de capacidades para lidar com as emoções, o que Vigotiski (2018) aponta como "educação dos sentimentos" - muitas vezes, não são possíveis fora da escola.

A escola tem papel essencial na formação humana em todos os aspectos da aprendizagem e do desenvolvimento. Para tanto, torna-se necessário que seus sujeitos, principalmente os professores, tomem consciência da integralidade dessa formação. "Os educadores precisam compreender seus educandos como sujeitos complexos, imbuídos de capacidade cognitiva, de emoções, sentimentos, experiências anteriores, etc.” (GAZZOTTI; SOUZA, 2019, p. 7). Desse modo, correse menos o risco de reduzir a organização do meio onde ocorre a aprendizagem ao desenvolvimento de uma capacidade em detrimento de todas as outras, tornando o sujeito uma mera “cópia parcial” das relações.

\section{O sentido e a emoção na atividade de estudo}

Nessa seção, a partir das reflexões que realizamos até aqui, fazemos o esforço para identificar o lugar do sentido e da emoção no motivo da atividade de estudo. O conteúdo externo e interno do motivo age nas emoções, que se traduzem em sentimentos a partir do êxito que se obtém na realização das tarefas da atividade. A concretização de uma tarefa se revela subjetivamente no sujeito, nas emoções e sentimentos que emergem no processo. Conforme Vigotsk (2018), há dois vieses de manifestação dessas emoções. Pela "natureza biológica" respondem corporalmente, como resultado das relações com o objeto no meio em que se realiza 
o contato. Pela "natureza psicológica" se expressam por sentimentos positivos ou negativos, decorrentes da "luta" entre dominar ou não estas relações.

O sentido da atividade que decorre da relação entre o motivo e a finalidade da atividade na relação com seus objetos (LEONTIEV, 2004), como vimos no texto anteriormente, remete a emoções e sentimentos positivos. Ou seja, uma vez que o estudante compreende as razões e os fins de suas ações de estudo, gera, para ele, um sentido e o confere um relativo domínio sobre as relações. A possibilidade de obter êxito na avaliação, porque está controlando o processo, amplia o universo do sentido de estudar para novas orientações. A estreita relação das razões e finalidades da atuação revela novas possibilidades para o sentido da atividade. Aquilo que lhe estimulava superficialmente pelo resultado de suas tarefas, por exemplo, a nota para mostrar aos pais, responde a novas necessidades, mais orientadas pelos objetos de conhecimento (que controlam a atividade), e menos a influência dos múltiplos estímulos que respondem as necessidades de carências.

Quando "o que se busca" converge com o "para que se busca" (DAVÍDOV, 1988), a atividade faz sentido e a necessidade atua como orientadora e reguladora das ações. Quando não convergem, a atividade não faz sentido. Nesse caso, a necessidade atua como carência no sujeito e o foco se orienta predominantemente ao resultado final, com mais ênfase em demandas singulares afetivo-emocionais. A atividade é alienada, pois gera estranhamento ao processo de produção e se move determinada por uma finalidade que não se liga com as ações da atividade.

Conforme o exposto na seção anterior, do mesmo modo que o reflexo psíquico revela o conteúdo da tomada de consciência da realidade, a vivência revela o conteúdo que manifesta a consciência do sujeito. A conduta do sujeito concreto, como personalidade (LEONTIEV, 1978), manifesta sua resposta subjetiva sob as determinações objetivas de sua atividade, no movimento que Davídov (1988) chama de exteriorização. Desse modo, no âmbito individual da atividade, pode-se analisar o que o sujeito produz e sua conduta, não apenas diante do produto final, mas principalmente nas etapas do processo de produção. 
Vale a discussão sobre a conduta de negação do estudante com relação ao estudo, entendendo que tal negação ocorre quando sua experiência (relação com os objetos da atividade) não gera um sentido positivo. Nas origens dessa negação, estão as possibilidades de transformação do ensino que se orienta para a organização de experiências de estudo geradoras de sentido positivo. Essas experiências, COM BASE NOS ESTUDOS QUE REALIZAMOS, atuam no motivo da atividade como sentido, porém, não encerradas nesse elemento. Uma vez que o sentido expressa a relação do motivo com a finalidade da ação de estudo, se revela para o estudante como impulsor de sua atuação. A necessidade externa da atividade se torna uma necessidade sua, o motivo apenas compreensível se torna eficaz (LEONTIV, 1978) e suas emoções, que esperavam conforto das carências pela satisfação de necessidades singulares, atuam como estímulos (energia) para desprender esforços voluntários na organização e realização das ações de estudo.

Nesse processo, compreendemos em unidade a "experiência/sentido", que se expressa pela vivência do sujeito na relação com o objeto da atividade. Para nós, toda experiência é verdadeira e se apresenta integralmente ao sujeito do estímulo (DAVÍDOV, 1988), que reflete em seu psiquismo o "conteúdo bruto" dessa experiência, incluindo suas emoções. A tomada de consciência do sujeito é o que torna a experiência parcial e limitada, positiva ou negativa, boa ou ruim, a partir do que o agrada ou não ao satisfazer suas necessidades, que se mostram como carência e orientação/controle (DAVÍDOV, 1988).

O sentido, portanto, não está na experiência que conforta as emoções do estudante, mas na relação dele com os objetos da atividade, nas razões pelas quais atua sobre o objeto e no que o orienta a partir dessa relação. Este, não surge o estudante sana as carências subjetivas, internas. Isso gera apenas um bem estar momentâneo ao organismo e cobre as emoções. As carências do organismo, que atuam no sujeito como desejos e necessidades, influindo em suas emoções, muitas vezes, não são possíveis sequer identificá-las.

Por mais detalhada que seja uma descrição, não conseguimos esmiuçar a vivência integral para a análise da relação do sujeito com o objeto da 
atividade. Todavia, na análise do sujeito em atividade de estudo, podemos identificar a estrutura comum das vivências, suas particularidades com base no contexto onde ocorre a atividade propriamente dita, como ela se organiza e as manifestações da conduta do sujeito como traços decorrentes do modo de organização do ensino. Portanto, se o estudante está "preso" às suas necessidades de carência é porque as relações em que está inserido não estão sendo suficientes para que se aproprie de novas necessidades.

Para identificar a estrutura das vivências na atividade de estudo, temos que compreender como a prática pedagógica se apresenta para o estudante. No Brasil, o ensino se estrutura em componentes curriculares que determinam a sua sistematização por áreas de conhecimento. Em cada área, os professores têm o compromisso de fazer valer o direito do estudante ao desenvolvimento pleno, garantido pela Lei de Diretrizes e Bases da Educação Nacional - LDB (Brasil, 1996). O ensino é regulado pelo tempo e conteúdo preestabelecidos nas propostas curriculares, manuais, leis e normativas, que variam conforme a gestão educacional de estados ou municípios, seguindo as orientações da Base Nacional Comum Curricular - BNCC (BRASIL, 2017) que passou a vigorar recentemente.

Esses documentos apresentam as razões e as finalidades da atividade de ensino e de estudo. A partir do modo de se estruturar a prática pedagógica nos documentos - junto ao complexo de múltiplas determinações socioculturais de cada região, sobretudo as condições de manutenção da vida dos estudantes e a infraestrutura escolar - os professores organizam o ensino. Para além dos fatores pedagógicos, o ensino escolar agrega um conteúdo que transcende os currículos ligados unicamente aos componentes curriculares (disciplinas) e sua organização.

"A educação, a vida escolar e as relações que os educandos vivenciam neste contexto histórico-cultural, portanto, funcionam como artefatos culturais mediadores das relações entre sujeitos e entre sujeito e meio social e cultural" (GAZZOTTI; SOUZA, 2019, p. 4). Como vimos no decorrer desse estudo, a realidade se apresenta de forma integral para o sujeito. Contudo, a organização curricular - devido à forma que se constroem os planejamentos escolares, muitas vezes, com modelos teóricos distantes do campo de compreensão dos 
professores - tem fragmentado a prática pedagógica e, por consequência, a atividade de estudo que se alicerça sobre bases abstratas.

Estas bases, na prática, não refletem as condições reais de atuação dos sujeitos escolares, que não se apropriam das finalidades concretas da atividade, dos procedimentos científicos (ações e operações) e de suas verdadeiras razões (motivos). A escola se torna extensão da vida extraescolar. A superficialidade na compreensão do estudante sobre as razões de sua participação na vida escolar não gera elementos "fortes" o suficiente para que se transformem em "motivos eficientes" para a atividade de estudo (LEONTIEV, 2004).

A falta de conteúdo concreto na base substancial que eleva o contato do estudante com os objetos de sua atividade, que gera o desejo pelo estudo e o move, se evidencia nas manifestações sobre a importância das relações escolares em sua vida. Ao escreverem sobre sua trajetória escolar (quando pedimos em sala de aula para relatarem sobre sua vida escolar), o estudante raramente destaca ações de ensino e estudo ligados à aprendizagem. O que toca o estudante, na maioria dos relatos, são circunstâncias que envolvem um ou outro professor que o apoiou ou o repreendeu em algum momento (necessidade por carência afetiva). É comum também a expressão de que "estuda para se dar bem na vida". Mas, a finalidade de se dar bem na vida não se expressa nas ações de estudo e nas razões da atividade. Sem relação entre os motivos e finalidades, a atividade não faz sentido para o estudante (LEONTIEV, 2004).

O estudante que não estabelece relações com o objeto de sua atividade não reconhece o conhecimento como essencial e primário. Isso, por não experimentar o conhecimento nessas condições e reconhecer o estudo como atividade principal. Desse modo, manifesta-se, junto aos professores, uma estrutura cristalizada em componentes curriculares com conteúdos que surgem com abstrações mecânicas que, às vezes, não fazem sentido nem para o professor. Nessas abstrações em que se acumulam os conteúdos e métodos de ensino, a necessidade do conhecimento se sacia com informações instantâneas.

Quando se mantém as bases abstratas, ocorre uma inversão de valores nos objetivos da educação escolar: ao invés de o estudante estudar para efetivamente 
se apropriar mais profundamente dos conhecimentos, o que o move é atingir a nota para obter aprovação no final do ano letivo. O conteúdo da atividade integral de estudo se reduz à satisfação de ser aprovado (ainda que não se aprenda muita coisa), ao medo da reprovação ou repousa na indiferença com relação à atividade de estudo. Ao contrário disso, o estudante que consegue estabelecer as relações com o objeto da atividade manifesta vontade pelo estudo, se frustra quando não ocorre a aprendizagem (mesmo com a nota) e busca em outros espaços métodos e conhecimentos que a escola não lhe possibilita.

É comum, há algum tempo, falar sobre as emoções no processo de ensino e aprendizagem. A Base Nacional Comum Curricular (BRASIL, 2018), em outra perspectiva teórica, apresenta como competência essencial no ensino escolar o desenvolvimento socioemocional do estudante. Consideram-na separada do sujeito concreto em atividade, diferenciando o que é competência socioemocional das relacionadas à apropriação dos conhecimentos e métodos de estudo, como se o cognitivo fosse um segmento do desenvolvimento e o afetivo emocional outro.

Para Leontiev (1978), a atividade em que o sujeito se insere, além das bases da formação da consciência, gera os nexos que constituem e transformam sua personalidade. De acordo com Vygotski (2012, p. 226), a personalidade em formação deve ser tratada a partir da "lei de transição de formas e modos de comportamentos naturais, imediatos, espontâneos, aos mediados e artificiais que surgem no processo do desenvolvimento cultural das funções psíquicas”. Nessa perspectiva, a apropriação dos conhecimentos científicos e a apreensão de seus métodos são as bases escolares do desenvolvimento humano em sua integralidade a partir da atividade de estudo. Desse modo, se quisermos transformar a conduta do estudante e sua postura com relação ao estudo, as atitudes movidas por carência na realização das tarefas escolares requisitam que sejam transformadas em atitudes movidas pela orientação e controle do próprio estudante sobre a atividade. $\mathrm{O}$ estudante tem que buscar as condições geradoras de motivos de sua atividade, atribuir-lhe um sentido na relação com os fins para o qual se orienta e “educar” seus sentimentos e emoções a favor da vontade de estudar. 


\section{Conclusões}

Expomos neste ensaio teórico um caminho para a investigação do conteúdo que move o estudante em atividade de estudo. A personalidade como resultado desse processo e não como condição, surge como possibilidade para compreender melhor a conduta do estudante nos espaços de aprendizagem. As emoções não podem ser a causa do não engajamento do estudante, mas uma possibilidade de seu desenvolvimento. A análise voltada para o sujeito concreto deve considerar, além das condições objetivas externas da atividade, as condições subjetivas internas do psiquismo, como as contingências psicoemocionais intra e extraescolares que fazem parte da vida do estudante.

O exposto no estudo trouxe a reflexão de que o estudante, alheio de sua atividade principal, não constitui os nexos com os interesses e necessidades próprios dela, tornando-os secundários nas relações. Se não atua efetivamente com objetos da atividade de estudo, as ações que realiza atendem fins distintos, desconexos da atividade. Com isso, o que move o estudante tem predominância em necessidades relacionadas às suas carências internas de autoafirmação, afeto, proteção, entre outras. A atividade de estudo nessas condições, não gera o sentido positivo, tão pouco o desejo e a vontade pelo estudo. Estar na escola se reduz em confortar suas emoções.

O contato com os objetos da atividade na forma de vivência pela relação do motivo com as finalidades da ação de estudo é o que gera o sentido positivo que se torna o combustível dos desejos (conferindo nova conotação para as emoções) e vontades do estudante (resignificando seu papel na realização das ações e tarefas escolares), que o impulsionam à atividade. Ao relacionar-se com o conhecimento científico e se apropriar dos métodos de estudo e movimentos conceituais, o estudante pode substituir e superar as necessidades que o movem. As emoções que se reduzem ao fim da atividade passam a ser direcionadas ao processo, de modo que a aprendizagem do próprio movimento da atividade proporcione a educação de seus sentimentos e um controle sobre si mesmo, sobre sua conduta. 


\section{Referências}

ASBAHR, F. S. F.; SOUZA, M. P. R. "Por que aprender isso, professora?" Sentido pessoal e atividade de estudo na Psicologia Histórico-Cultural. Estudos de Psicologia, jul/set, 2014, p. 157-238. DOI: https://doi.org/10.11606/t.47.2011.tde24032011-094830.

BLAGONADEZHINA, L. V. Las Emociones y los Sentimientos. Cap. XII. In: SMIRNOV, A. A.; LEONTIEV, A. N.; RUBINSHTEIN, S. L.; TIEPLOV, B. N.. Psicologia. Tradução de Florencio Villa Landa. 4. ed. México: Grijalbo, p. 355 384, 1978.

BRASIL. Lei de Diretrizes e Bases da Educação Nacional. Lei n ${ }^{\circ}$ 9.394, de 20 de dezembro de 1996. Estabelece as diretrizes e bases da educação nacional. Diário Oficial da União, Brasília, 23 de dezembro de 1996. Disponível em:

http://www.planalto.gov.br/ccivil_03/leis/L9394.htm. Acesso em: 05 fev. 2021.

BRASIL. Ministério da Educação. Secretaria de Educação Básica. Base Nacional Comum Curricular (BNCC). Brasília, DF: MEC, 2018. Disponível em: http://basenacionalcomum.mec.gov.br/images/BNCC_EI_EF_110518_versaofinal_ site.pdf. Acesso em: 05 fev. 2021.

DAVÍDOV, V.. La Enseñanza Escolar y el Desarrollo Psiquico: investigacion psicológica teórica y experimental. (M. Shuare, Trad). Moscu: Progreso, 1988.

DAVIDOV, V. V.; MÁRKOVA, A. (1987). La concepcion de la actividad de estudio de los escolares. In: Davidov, V.; Shuare, M. (Orgs.), La psicología evolutiva y pedagogía en la URSS: antología. (pp. 316- 337). Moscou: Progreso.

GAZZOTTI, DANIELE; DE SOUZA, MARILENE PROENÇA REBELLO. A emoção e o ensino-aprendizagem em uma perspectiva histórico-cultural: uma pesquisa na educação infantil bilíngue. Obutchénie. Revista de Didática e Psicologia Pedagógica, p. 1-23, 2019. DOI:

https://doi.org/10.14393/OBv3n2.a2019-51562.

LEONTIEV, A. Actividad, Conciencia y Personalidad. Buenos Aires: Ciencias del Hombre, 1978.

LEONTIEV, A. O desenvolvimento do psiquismo. Tradução de R. E. Frias. São Paulo: Centauro, 2004.

LUKÁCS, GYÖRGY. Para uma ontologia do ser social I. Tradução de Carlos Nelson Coutinho, Mario Duayer e Nélio Schneider. São Paulo: Boitempo, 2012.

MARX, K. \& ENGELS, F. Oposicion entre las concepções materialistas e idealistas. In: Marx, K. \& Engels, F. (Orgs). Obras Escogidas: Tomo I. Moscú: Progreso, p. 11-81, 1974. 
MENDONÇA, A. B. J.; ASBAHR, F. S. F. Atividade de estudo e sentido pessoal: uma revisão teórica. Obutchénie. R. de Didat. e Psic. Pedag. Uberlândia, MG, v.2, n.3, set./dez. 2018. p.780-800. DOI: https://doi.org/10.14393/OBv2n3.a2018-47450.

PIOTTO, D. C.; ASBAHR, F. S. F.; FURLANETO, F. R. Significação, e sentido na psicologia histórico-cultural: implicações para educação escolar. In: MOURA, Manoel Oriosvaldo (Org.). Educação escolar e pesquisa na teoria históricocultural. São Paulo: Edições Loyola, 2017. p. 101-124.

VYGOTSKI, L. S. Obras Escogidas II. Madrid. Machado Libros S.A. 2ed, 2001. VYGOTSKI, L. S. Obras Escogidas IV: Paidologia del adolescente. Problemas de la psicologia infantil. España: Madrid. Machado Grupo de Distribucion, S.L, 2012.

VIGOTSKI, L. S. Psicologia Pedagógica. Tradução de Paulo Bezerra. São Paulo: Martins Fontes, 2018. 